\title{
Different stability of social-communication problems and negative demanding behaviour from infancy to toddlerhood in a large Dutch population sample
}

Esmé Möricke ${ }^{1 *}$, GA Martijn Lappenschaar ${ }^{1}$, Sophie HN Swinkels ${ }^{1}$, Nanda NJ Rommelse ${ }^{1,3}$ and Jan K Buitelaar ${ }^{2,3}$

\begin{abstract}
Background: Little is known about the stability of behavioural and developmental problems as children develop from infants to toddlers in the general population. Therefore, we investigated behavioural profiles at two time points and determined whether behaviours are stable during early development.

Methods: Parents of 4,237 children completed questionnaires with 62 items about externalizing, internalizing, and social-communicative behaviour when the children were 14-15 and 36-37 months old. Factor mixture modelling identified five homogeneous profiles at both time points: three with relatively normal behaviour or with mild/moderate problems, one with clear communication and interaction problems, and another with pronounced negative and demanding behaviour.

Results: More than $85 \%$ of infants with normal behaviour or mild problems at 14-15 months were reported to behave relatively typically as toddlers at 36-37 months. A similar percentage of infants with moderate communication problems outgrew their problems by the time they were toddlers. However, infants with severe problems had mild to severe problems as toddlers, and did not show completely normal behaviour. Improvement over time occurred more often in children with negative and demanding behaviour than in children with communication and interaction problems. The former showed less homotypic continuity than the latter.
\end{abstract}

Conclusions: Negative and demanding behaviour is more often transient and a less specific predictor of problems in toddlerhood than communication and interaction problems.

Keywords: Factor mixture modelling, Behavioural and developmental profiles and problems, Continuity and stability, Infants and toddlers, General population

\section{Background}

Psychiatric disorders, such as those defined by the Diagnostic and Statistical Manual of mental disorders (DSM-IV-TR) [1] and the International Statistical Classification of Diseases and related health problems (ICD-10) [2], are often preceded by dysfunctioning in the first years of life [3-5], and investigators are becoming increasingly aware that, in order to understand why and how psychiatric

\footnotetext{
* Correspondence: E.Moricke@psy.umcn.nl

'Department of Psychiatry, Nijmegen Centre for Evidence-Based Practice, Radboud University Nijmegen Medical Centre, P.O. Box 9101, 6500 HB Nijmegen, The Netherlands

Full list of author information is available at the end of the article
}

disorders occur, it is important to look for relevant signs as early as possible, in infancy. A major barrier to this is that the DSM-IV-TR and the ICD-10 are not suitable for studying behavioural and developmental problems in children younger than 2 years, because at this age there are no specific criteria and categories for the majority of psychiatric disorders and their precursors [6,7]. In addition, these classification systems, as well as the Diagnostic Classification of mental health and developmental disorders of infancy and early childhood (DC 0-3R) [8], contain fixed algorithms that offer few possibilities for classifying children who score just below the diagnostic cut-off (milder cases), but who may be at serious risk for later 
disorders. For instance, severe social-communication problems, which are characteristic for autism spectrum disorder (ASD), may be apparent and lead to a reliable diagnosis before 2 years of age, whereas less pronounced problems are only recognized later [9]. This hinders the investigation of the continuity of psychiatric dysfunctioning over time.

A statistical approach may be an alternative way to investigate coherent patterns of behaviour and their stability from infancy to toddlerhood and may obviate the limitations of regular classification systems. Factor mixture modelling (FMM) [10] combines a common factor analysis (FA) with a latent class analysis (LCA) [11]. FA makes the determination of the unobserved factors underlying the observed variables possible. LCA, based on an empirically bottom-up approach, enables the classification of children into mutually exclusive groups on the basis of the type and/or severity of behaviour. The advantage is that not only groups with deviant behaviour, but also with only mild problems or without problems can be formed, which provides a better overall view of symptom severity. Thus, FMM gives insight in both the clustering of items into factors and the grouping of individuals into classes representing all possible dimensions. Application of this method at several time points makes it possible to distinguish groups of children with different developmental patterns [12]: stable without problems, transitory problems, late-onset problems, and stable with problems, either the same problems (homotypic continuity) or different problems (heterotypic continuity) [13,14].

The preferred way to study changes in behaviour over time is to use a longitudinal, large-scale population-based design, because this design is the least biased with regard to frequency of disorders, symptom severity, and level of impairment. In addition, specific diagnostic algorithms can be used, adjusted for age or developmental level $[3,15]$. However, there have been only a few prospective studies focusing on the prevalence and stability of behavioural and emotional problems in infants and toddlers.

Briggs-Gowan et al. [14] studied the stability of socialemotional and behavioural problems over 1 year in infants and toddlers and found half of their sample to have persistent psychopathology. Homotypic persistence rates were about $38 \%$ for internalizing behaviour, $50 \%$ for externalizing behaviour, and $39 \%$ for dysregulation. Heterotypic persistence was considerably lower (12\%). Mathiesen and Sanson [12] found that nearly $12 \%$ of children had problems of emotional adjustment, social adjustment, overactive-inattentive behaviour, and regulation at both 18 and 30 months of age. However, the type of stability was only determined within each separate factor, and not between various factors, so the study did not provide information about heterotypic continuity. In a follow-up study of the same sample [16], the authors found that undercontrolled problems decreased and internalizing problems increased up to age 4.5 years; however, the number of items was limited and only these two types of symptoms were considered. Bufferd, Dougherty, Carlson, Rose, and Klein [17] assessed psychiatric disorders in preschoolers. Having a psychiatric diagnosis at 3 years led to a fivefold greater risk of having such a diagnosis at 6 years, and 14\% of the children met criteria at both time points. Homotypic continuity occurred for anxiety, attention-deficit/ hyperactivity disorder (ADHD), and oppositional defiant disorder (ODD), whereas heterotypic continuity existed between anxiety and depression, anxiety and ODD, and ADHD and ODD. Beyer, Postert, Müller, and Furniss [18] investigated the continuity of, and the changes in, two types of symptoms over a 4-year period from preschool to primary school. The continuity of internalizing symptoms (37\%) was higher than that of externalizing symptoms (19\%), but there was substantial crossover from externalizing to internalizing symptoms (15\%) and from externalizing symptoms to a combination of both types of problems (18\%). The authors also reported that $86 \%$ of children without mental health problems at preschool did not have such problems at primary school. Further evidence for the stability of preschool behavioural and emotional problems in relation to psychopathology in childhood and adolescence exists [3,19].

Previous population-based studies included up to 1,000 participants, but mainly focused on clusters of variables and used cut-off values to classify children into two groups (with or without problems), which resulted in a loss of information. Moreover, emphasis was often on deviant and problematic behaviour, and normal behaviour and improvement of functioning were not always considered. Previously, we investigated normal and deviant behaviour in a population-based sample involving 6,330 infants aged 14-15 months by combining a dimensional and categorical approach [20]. Parents answered items about externalizing, internalizing, and social-communicative behaviour which could be divided over nine factors, namely deviant communication, negative emotionality, deviant reactive behaviour, deviant play behaviour, demanding behaviour, social anxiety/inhibition, advanced social interaction problems, basic social interaction problems, and sleep problems. LCA identified five homogeneous profiles, three of which were indicative of increased problems: one was related to moderate communication problems, another to severe communication and social interaction problems, and the last to severe negative and demanding behaviour. Thus, certain behavioural and developmental profiles can be recognized at the age of 14-15 months, but the key question is how stable these profiles are. The aim of the current study was to explore the stability of normal, externalizing, internalizing, and social-communicative behaviour from 
infancy to toddlerhood. To this end, we investigated (1) which homogeneous profiles can be identified in these children at the age of 36-37 months, and (2) to what extent these profiles are stable passing from infancy to toddlerhood.

\section{Methods \\ Participants}

The Medical Ethics Committee of the University Medical Centre Utrecht approved the study. We used a subsample from a birth cohort of children born between August 2000 and August 2001 in the province of Utrecht, The Netherlands $(N=12,297)$. Parents received two questionnaires concerning infant behaviour and development: one at T1, when their child was $14-15$ months old $(M=14.70$; $S D=0.68)$, and another at T2, when their child was 36-37 months old $(M=36.64 ; S D=2.63)$. Parents who returned the questionnaires automatically consented to participate. Children were included if they had maximally six missing values ( $<10 \%$ of 62 items) on each questionnaire (thus at both time points), resulting in 4,237 participants (i.e., a response rate of $34.5 \%$ of 12,297 children eligible). At both time points, the questionnaire was mainly completed by mothers: T1 mothers $84.4 \%(n=3,575)$, fathers $10.2 \%$ $(n=431)$, both parents $0.3 \%(n=14)$, and unknown respondent $5.1 \%(n=217)$; T2 mothers $89.2 \%(n=3,779)$, fathers $9.3 \%(n=392)$, both parents $0.3 \%(n=13)$, and unknown respondent $1.3 \%(n=53)$. In at least $82.1 \%$ of the cases the respondent was the same at T1 and T2. The sample consisted of 2,176 boys (51.4\%) and 2,061 girls (48.6\%). Most children were developing normally, as evaluated by the parents. Of all children, 54 (1.3\%) had a mental or physical handicap, 176 (4.2\%) had a physical disease, and 286 (6.8\%) used medication; health information was missing for 6 children (0.1\%). They were all included in the analyses, because we wanted to explore the behaviour of all types of children.

Because access to information about non-responders was not allowed, we investigated the possibility of selection bias by comparing the data of responders with demographic data for the general population [21]. Classified according to nationality, the majority of the sample was Dutch $(94.6 \%, n=4,009)$, with smaller groups of other minorities: $1.4 \%$ other European $(n=60), 1.6 \%$ Moroccan or Turkish $(n=67)$, and $2.0 \%$ others $(n=84)$; the nationality of $0.4 \%$ of the sample was not known $(n=17)$. More than $97.5 \%$ of the children belonged to the Caucasian race, so the chance that racial differences played a meaningful role was limited. Our sample contained more Dutch children than the population average (82.1\%). More parents in this sample had a high educational level (college or university degree) than in the general population (mothers: $45.4 \%$ versus $38.9 \%$; fathers: $46.6 \%$ versus $36.0 \%$ ). The socioeconomic status (SES), based on mean level of education and occupation of both parents, varied from low $(n=477 ; 11.3 \%)$ through moderate $(n=1,668 ; 39.4 \%)$ to high $(n=2,069 ; 48.8 \%)$; in $0.5 \%$ $(n=23)$ of the cases SES was unknown.

\section{Instruments}

\section{Utrecht Screening Questionnaire}

The Utrecht Screening Questionnaire (USQ) [22], which is completed at age 14-15 months (T1), was specially developed by a multidisciplinary panel of experts with clinical and research experience with infants and toddlers. The panel selected 79 items from a large pool of potentially interesting and relevant items from well-validated instruments, namely, the Child Behavior Checklist 11/2-5 [23], the Infant-Toddler Social and Emotional Assessment [24], the Vineland Social-Emotional Early Childhood Scales [25], and the Early Screening of Autistic Traits Questionnaire (ESAT) [26,27]. The two selection criteria were that the items were specific for externalizing, internalizing, or social-communicative problems, and that they were suitable for children younger than 18 months. Subsequently, we excluded 17 less relevant items: 12 items were rather identical to other items in the same questionnaire, and 5 items were related more to aspects of parental child rearing than to child behaviour. In total 62 items were left (Table 1). Fourteen ESAT items were scored on a yes or no scale (corresponding with scores 0 or 1 ) and the other 48 items were rated on a three-point Likert scale (0 'not at all true', 1 'somewhat/sometimes true', 2 'clearly/often true'). See Möricke et al. [20] for a more detailed description of previous analyses.

\section{Social Behaviour Questionnaire}

The Social Behaviour Questionnaire (SBQ), which is completed at age 36-37 months (T2), focuses on the externalizing, internalizing, and social-communicative behaviour of toddlers. It consists of 62 items scored on a three-point Likert scale: 54 items were formulated exactly the same as in the USQ, but 6 items were adapted to the higher level of functioning expected of toddlers in comparison with infants, and 2 items were new (Table 2). The answer possibilities of the 14 ESAT items changed from yes/no to the three-point Likert scale.

\section{Statistical approach}

To interpret all items similarly, some items were reversely coded. A score of 0 meant that a child showed normal behaviour; a score of 1 or 2 implied that a child lacked competences or experienced problems to a mild or severe degree. The items were considered as ordinal variables, had the same weight, and were of equal importance. Maximally six missing values on each questionnaire were allowed, and these values were imputed by means 
Table 1 Proportion of children with deviant scores on USQ items in exploratory factor analysis with promax rotation at $\mathrm{T} 1(N=4,237)$

\begin{tabular}{|c|c|c|}
\hline Item USQ ${ }^{\mathrm{a}}$ & Factor USQ ${ }^{\mathrm{a}}$ & Proportion of children \\
\hline & 1 Deviant communication & \\
\hline $47^{b}$ & Uses gestures appropriately to express him/herself & 16.0 \\
\hline $48^{b}$ & Points at things to show ${ }^{c}$ & 6.2 \\
\hline $46^{b}$ & Understands at least ten words ${ }^{c}$ & .4 \\
\hline $45^{b}$ & Imitates simple gestures ${ }^{c}$ & $4.6^{\mathrm{d}}$ \\
\hline $75^{\mathrm{b}}$ & Uses common names like 'mummy/daddy'c & 0 \\
\hline $14^{\mathrm{b}}$ & Gives or shows something to somebody & 2.0 \\
\hline $74^{b}$ & Imitates sounds made by parents ${ }^{c}$ & 3.1 \\
\hline $76^{\mathrm{b}}$ & Reacts when name is called & $8^{\mathrm{d}}$ \\
\hline $41^{b}$ & Pays attention when being spoken to & 10.1 \\
\hline
\end{tabular}

2 Negative emotionality

Is stubborn, sullen or irritable

Is fussy, whiny

Is extremely loud

Is uncooperative

Changes mood suddenly $\quad 4.1$

Screams a lot $\quad 4.0$

Is easily upset $\quad 6.7$

Cries a lot $\quad 2.5$

Cannot sit still; is restless or hyperactive $\quad 9.8$

Seems unhappy without clear reason $\quad 4.7^{d}$

Bites, hits or kicks others $\quad 0.9$

Hurts animals or persons $\quad 1.5$

Cannot concentrate or pay attention for long $\quad 8.0$

Refuses to play active games him/herself $\quad 1.2$

Wants help constantly 2.5

Will not share toys or other things $\quad 5.7$

3 Deviant reactive behaviour

Reacts when being spoken to

Reacts normally to sensory stimuli

Shows clear facial expressions 
Table 1 Proportion of children with deviant scores on USQ items in exploratory factor analysis with promax rotation at T1 $(N=4,237)$ (Continued)

\begin{tabular}{|c|c|c|c|}
\hline & 7 Advanced social interaction problems & & 0.49 \\
\hline $53^{b}$ & Shows that he/she distinguishes parents from others & $9.7^{d}$ & \\
\hline $70^{\mathrm{b}}$ & Babbles or makes noises spontaneouslyc & $5.7^{d}$ & \\
\hline $61^{b}$ & Utters sounds of joy & $6.8^{d}$ & \\
\hline $26^{\mathrm{b}}$ & Shows interest in new objects/persons & $7.1^{d}$ & \\
\hline $79^{b}$ & Follows with eyes when someone moves ${ }^{c}$ & $8.8^{d}$ & \\
\hline $71^{b}$ & Stops wailing when being spoken to & 5.6 & \\
\hline $43^{b}$ & Reaches when he/she wants to be held & 1.9 & \\
\hline \multirow[t]{2}{*}{$35^{\mathrm{b}}$} & Enjoys learning new things & 2.2 & \\
\hline & 8 Basic social interaction problems & & 0.18 \\
\hline $17^{b}$ & Directs social smile to parents and others & 0.4 & \\
\hline $11^{\mathrm{b}}$ & Makes eye contact easily & 1.9 & \\
\hline $16^{\mathrm{b}}$ & Likes cuddling & 4.2 & \\
\hline \multirow[t]{2}{*}{13} & Repeats stereotypic movements & 5.5 & \\
\hline & 9 Sleep problems & & 0.32 \\
\hline 39 & Cannot sleep alone & 4.1 & \\
\hline 63 & Finds it difficult to fall asleep & 7.0 & \\
\hline $51^{b}$ & Clings on when he/she wants to be held & 3.4 & \\
\hline
\end{tabular}

of single imputation using expectation maximization techniques [28].

Previous results of the exploratory factor analysis (EFA) of USQ data in the large population-based sample $(N=6,330)$ at T1 were considered valid and reliable [20]. Therefore, they served as starting point for the analyses of the USQ data in the smaller sample $(N=4,237)$ at T2. Although the number of items was reduced, from 74 in the USQ to 62 in the SBQ, roughly the same factor solution was used. The factors at T2 were determined by EFA, which was executed using the weighted least squares means and variance-adjusted (WLSMV) estimator. The optimal number of factors was based on the bend in the scree-plot, a small root mean square residual (RMSR), no or a few negative estimated residual variances (ERVs), and an intelligible interpretation of the factors. Internal consistency and variance explained were computed to establish reliability. Correlations between factors of the SBQ were calculated to get insight into their interrelatedness.

To examine the existence of unobserved population heterogeneity, factor mixture models (FMM) [10] were applied at T1 and T2 separately. FMM classifies individuals in homogeneous groups (latent classes), just as in cluster analysis and latent class analysis (LCA). In a standard LCA, variables are considered to be conditionally independent within each class. In contrast, in FMM it is assumed that variables within each class can be combined using a common factor analysis. Both factor division and class membership are latent, i.e., it is neither directly known how a subject scores on the underlying factors, nor to which class a subject belongs, but this information can be gathered later on. The FMMs were performed using the maximum likelihood estimator with robust standard errors (MLR). The best fitting model was identified on the basis of low (sample-size adjusted) Bayesian information criterion ((SSA) BIC) values, significant $p$-values like Vuong-Lo-Mendell-Rubin likelihood ratio test (VLMR LRT) and Lo-Mendell-Rubin adjusted likelihood ratio test (LMR adj. LRT), high entropies, and clear interpretations of the classes/profiles [29]. Children could only be admitted to one class. The distributions of respondent, sex, nationality, and SES were analysed across classes by means of crosstabs, Chi-square tests, and adjusted residuals. Differences in mean age per class were evaluated with one-way ANOVA and Bonferroni corrected post hoc tests.

After FMM, weighted factor scores were computed by dividing the obtained factor sum score by the maximum factor sum score, first for each individual and later for 
Table 2 Proportion of children with deviant scores and factor loadings on SBQ items in factor mixture model at T2 $(N=4,237)$

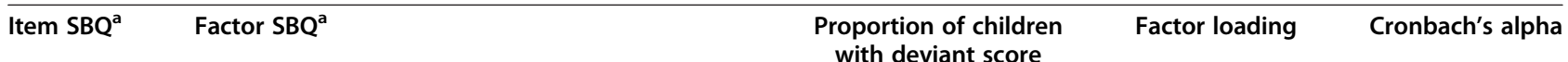

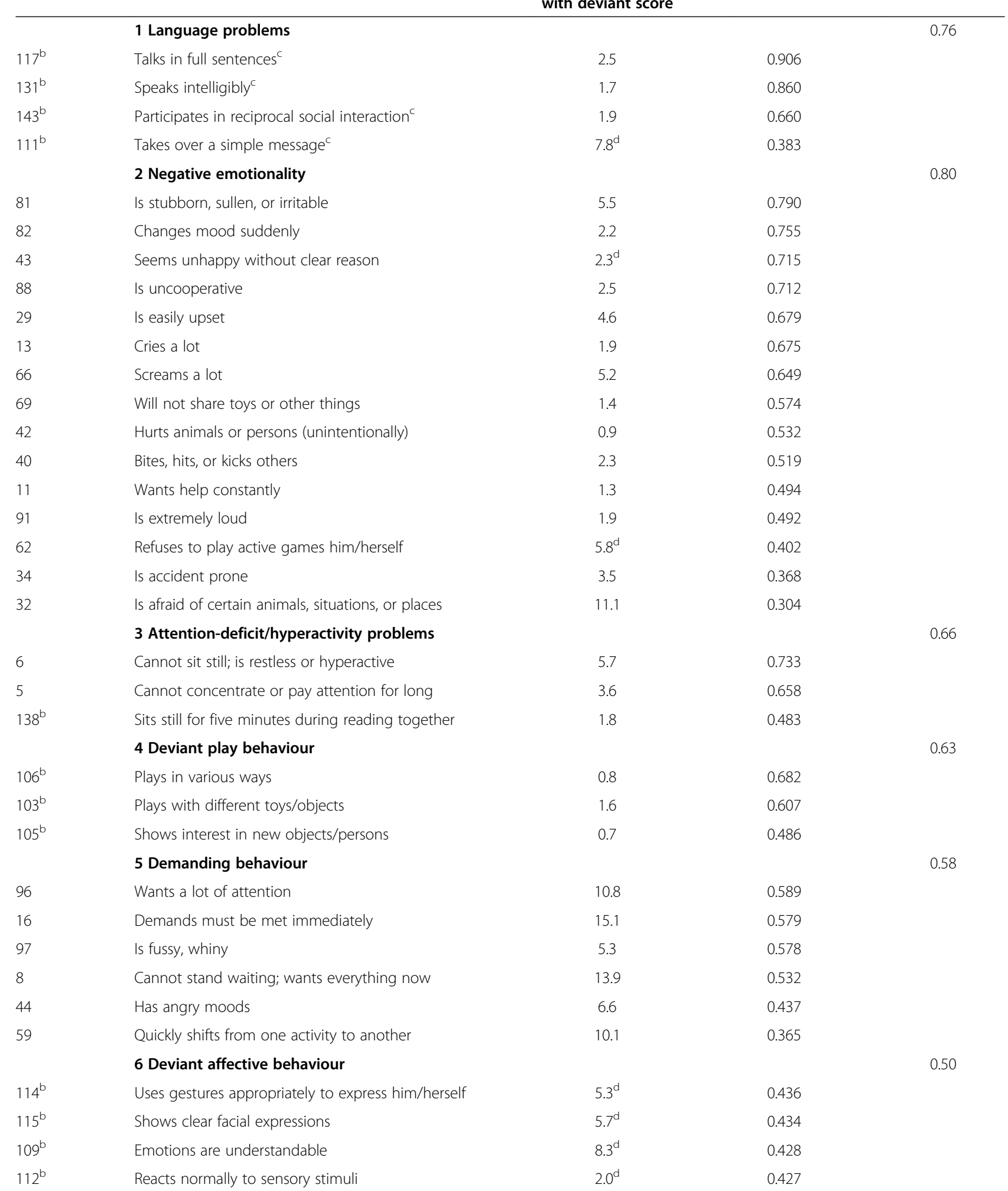


Table 2 Proportion of children with deviant scores and factor loadings on SBQ items in factor mixture model at T2 $(\mathbf{N}=\mathbf{4 , 2 3 7})$ (Continued)

\begin{tabular}{|c|c|c|c|c|}
\hline & 7 Communication and interaction problems & & & 0.78 \\
\hline $136^{\mathrm{b}}$ & Directs social smile to parents and others & $4.1^{\mathrm{d}}$ & 0.783 & \\
\hline $135^{\mathrm{b}}$ & Follows glance of parents ${ }^{c}$ & 2.7 & 0.718 & \\
\hline $129^{b}$ & Uses sounds or words to get attention or help ${ }^{c}$ & 2.5 & 0.662 & \\
\hline $123^{b}$ & Clings on when he/she wants to be held & 1.0 & 0.660 & \\
\hline $130^{\mathrm{b}}$ & Shows interest in other children/adults & $7.8^{d}$ & 0.646 & \\
\hline $125^{b}$ & Utters sounds of joy & 1.1 & 0.642 & \\
\hline $127^{b}$ & Gives or shows something to somebody & 0.8 & 0.616 & \\
\hline $139^{b}$ & Likes to play games with others & $3.7^{d}$ & 0.611 & \\
\hline $142^{b}$ & Reacts when being spoken to & $3.7^{\mathrm{d}}$ & 0.526 & \\
\hline $137^{b}$ & Pays attention when being spoken to & 0.7 & 0.509 & \\
\hline $121^{b}$ & Asks attention when being alone & 6.0 & 0.531 & \\
\hline $141^{b}$ & Reacts when name is called & $3.7^{\mathrm{d}}$ & 0.511 & \\
\hline $132^{b}$ & Enjoys learning new things & $7.1^{d}$ & 0.499 & \\
\hline $120^{b}$ & Shows that he/she distinguishes parents from others & $3.8^{\mathrm{d}}$ & 0.486 & \\
\hline $133^{\mathrm{b}}$ & Likes cuddling & $8.7^{d}$ & 0.485 & \\
\hline $118^{\mathrm{b}}$ & Makes eye contact easily & $7.9^{\mathrm{d}}$ & 0.471 & \\
\hline $104^{b}$ & Reaches when he/she wants to be held & 7.6 & 0.456 & \\
\hline $134^{\mathrm{b}}$ & Stops wailing when being spoken to & 1.7 & 0.446 & \\
\hline $128^{\mathrm{b}}$ & Uses objects for imaginative play & 1.0 & 0.445 & \\
\hline $122^{b}$ & Wants to do things him/herself & $7.6^{d}$ & 0.420 & \\
\hline \multirow[t]{2}{*}{$108^{b}$} & Imitates complex tasks ${ }^{c}$ & 6.3 & 0.361 & \\
\hline & 8 Sleep problems & & & 0.67 \\
\hline 22 & Cannot sleep alone & 6.5 & 0.815 & \\
\hline 38 & Finds it difficult to fall asleep & 5.7 & 0.762 & \\
\hline
\end{tabular}

each class as a whole. These continuous factor scores with values between 0 and 1 enable the comparison of classes on several factors within one instrument at one moment (either USQ or SBQ), and the comparison of classes on similar factors between two instruments at different time points (both USQ and SBQ). The overall size and significance of differences between classes were determined with one-way ANOVA and Bonferroni corrected post hoc tests. More precise differentiations between the classes were given by Cohen's $d$ effect sizes. These data provided information about qualitative and quantitative differences in weighted factor scores. Analyses were repeated with sex as covariate to determine whether it was necessary to distinguish between boys and girls.

To gain insight into the stability of behavioural problems over time, we used a variable- based and a person-based approach. To establish the specific stability of problem domains over time, we made a matrix with correlations between the factors of the USQ (T1) and the SBQ (T2). To determine the continuity of behavioural and developmental profiles over the 2-year period, a crosstab with percentages and adjusted residuals $(M=0$ and $S D=1$ ) was produced. Relevant transitions between classes from USQ to SBQ were depicted in a transition model. Next, we computed a dummy variable $(0=$ dropouts; 1 = follow-ups) and tested for selective attrition per nationality, SES, sex and class through crosstabs and Chi-square tests. Thereafter, we analysed per class whether the children who completed the follow-up were representative of the whole class. Independent samples T-tests were used to determine whether weighted factor scores for drop-outs and follow-ups differed significantly. Analyses were carried out with Mplus version 4.1 [30] or SPSS 17.0 [31]. 


\section{Results}

Previous analyses of USQ data at T1 $(N=6,330)$ revealed nine factors and five classes/profiles of which three were indicative of increased problems [20]. Information regarding factor solution, class division, and profiles for the sample with 4,237 children for whom data were available at T2 are presented in Tables 1, 2, 3, 4 and 5, and Figure 1.

\section{Factors at 36-37 months}

The structure of behaviour was examined by entering all 62 items in EFA, but only those (58) with factor loadings $\geq 0.30$ were used. Each item was assigned to the factor on which it had the highest loading; cross-loadings were neglected. All meaningful factors (with an eigenvalue $\geq 1.40$ ) were included. A solution with eight factors seemed to be best, because the RMSR was acceptably small (0.0339) and there were no negative ERVs. The factors were termed language problems, negative emotionality, attention-deficit/hyperactivity problems, deviant play behaviour, demanding behaviour, deviant affective behaviour, communication and interaction problems, and sleep problems (Table 2).

The internal consistency (Cronbach's alpha) of the separate factors varied from 0.50 to 0.80 (Table 2). The factors with a poor or questionable internal consistency mostly contained a small number of items and/or items that assess rare or rather extreme behaviour. The percentages of variance explained amounted to $37.8 \%$. When all 58 items were considered together, internal consistency was good $(\boldsymbol{\alpha}=0.84)$ and variance explained was $72.5 \%$. Interrelationships between the eight factors of the SBQ were computed, resulting in 28 correlations: 10 were negligible $(r<0.10)$, 13 were small $(r=0.10-0.30)$, and 5 were moderate $(r=0.30-0.50)$. Communication and interaction problems correlated with language problems $(r=0.42)$ and deviant play behaviour $(r=0.36)$; negative emotionality correlated with language problems $(r=0.36)$, ADHD problems $(r=0.33)$, and sleep problems $(r=0.33)$.
The factor solutions at 14-15 and 36-37 months were comparable, but in toddlerhood there was one factor less, the content of the factors was slightly different, and the factor 'language problems' was more prominent than in infancy.

\section{Classes and profiles at $\mathbf{3 6 - 3 7}$ months}

FMM identified specific behavioural and developmental profiles as well as the accompanying proportions of children. Table 3 shows the measures of fit and accuracy. The (SSA)BIC continued to decline up till seven classes. However, a 7-class solution was not better in LRT values than a 6-class solution, but the 6-class solution showed improvement over the 5-class solution. Based on these criteria we should have chosen the 6-class solution. However, this significant difference was mainly due to the large population size. The 6-class solution showed an extra normal group in comparison to the 5-class solution. In both solutions, the total number of children with typical behaviour was comparable. The corresponding profiles were very similar and showed only small differences in severity. Because the groups reflecting normal behaviour were of minor clinical importance, and because an equal number of analogous groups at $\mathrm{T} 1$ and $\mathrm{T} 2$ will lead to a clearer transition model, the 5-class solution was adopted.

A total of $31.4 \%$ of the children belonged to class 1 , $36.7 \%$ to class $2,9.3 \%$ to class $3,17.1 \%$ to class 4 , and $5.5 \%$ to class 5 . There were no significant differences in respondent (same or different) between the classes, neither at T1 $\left(\chi^{2}=0.086\right)$ nor at T2 $\left(\chi^{2}=0.280\right)$. Age differed significantly between the classes $(p<0.001)$, with children in class 2 being 10 days younger ( $M=36.44$ months) than the children in the other classes, who were about the same age ( $M=36.77$ months). The distribution of boys and girls in the five classes did not differ significantly from the overall mean distribution. Class 1 consisted of many Dutch children (96.5\%) and children from families with

Table 3 Summary of results of factor mixture modelling of USQ and SBQ $(N=4,237)$

\begin{tabular}{|c|c|c|c|c|c|c|}
\hline & \multirow{3}{*}{$\begin{array}{l}\text { Classes } \\
\text { Number }\end{array}$} & \multicolumn{3}{|c|}{ General tests of model fit } & \multicolumn{2}{|c|}{ Technical 11 output } \\
\hline & & & PIC & ccapir & VLMR LRT & LMR adj. LRT \\
\hline & & Entropy & BIC & SSA BIC & $p$-value & $p$-value \\
\hline \multirow{3}{*}{ USQ (T1) } & 4 & 0.823 & $275,706.768$ & $274,928.260$ & 0.0000 & 0.0000 \\
\hline & 5 & 0.821 & $274,767.281$ & $273,890.269$ & 0.0007 & 0.0007 \\
\hline & 6 & 0.806 & $274,233.404$ & $273,257.887$ & 1.0000 & 1.0000 \\
\hline \multirow{4}{*}{ SBQ (T2) } & 4 & 0.873 & $271,474.396$ & $270,759.440$ & 0.0000 & 0.0000 \\
\hline & 5 & 0.862 & $269,513.215$ & $268,744.240$ & 0.0037 & 0.0038 \\
\hline & 6 & 0.853 & $268,265.297$ & $267,442.303$ & 0.0039 & 0.0040 \\
\hline & 7 & 0.861 & $267,610.793$ & $266,733.781$ & 0.1297 & 0.1311 \\
\hline
\end{tabular}

Note. Entropy indicates classification accuracy. BIC Bayesian Information Criterion, SSA BIC Sample-Size Adjusted Bayesian Information Criterion, VLMR LRT Vuong-Lo-Mendell-Rubin Likelihood Ratio Test, LMR adj. LRT Lo-Mendell-Rubin Adjusted Likelihood Ratio Test. 
Table 4 Prevalence estimates and distribution of age, sex, nationality, and SES for five-class-model of USQ and SBQ $(N=4,237)$

\begin{tabular}{|c|c|c|c|c|c|c|c|c|}
\hline USQ (T1) & Class $1 n(\%)$ & Class $2 n(\%)$ & Class 3 n (\%) & Class $4 n(\%)$ & Class $5 n$ (\%) & Total $n(\%)$ & $d f$ & $F ; p$ (age) $\chi^{2} ; p$ (others) \\
\hline Age (child) (M, SD) & $14.71(0.65)$ & $14.74(0.76)$ & $14.68(0.55)$ & $14.56(0.56)^{*}$ & $14.72(0.64)$ & $14.69(0.68)$ & 4,4216 & $9.08 ;<0.001$ \\
\hline Sex (child) & & & & & & & 4 & $21.60 ;<0.001$ \\
\hline Boys & $651(46.6)^{b}$ & $793(52.3)$ & $98(53.0)$ & $401(55.2)$ & $233(56.3)$ & $2,176(51.4)$ & & \\
\hline Girls & $745(53.4)^{\mathrm{a}}$ & $723(47.7)$ & $87(47.0)$ & $325(44.8)$ & $181(43.7)$ & 2,061 (48.6) & & \\
\hline Nationality (child) & & & & & & & 8 & $60.71 ;<0.001$ \\
\hline Dutch & $1,354(97.0)^{\mathrm{a}}$ & $1,432(94.5)$ & $160(86.5)^{b}$ & $692(95.3)$ & $375(90.6)^{b}$ & $4,013(94.7)$ & & \\
\hline Non-Dutch & $39(2.8)^{b}$ & $77(5.1)$ & $25(13.5)^{a}$ & $32(4.4)$ & $38(9.2)^{a}$ & $211(5.0)$ & & \\
\hline SES (parents) & & & & & & & 12 & $130.88 ;<0.001$ \\
\hline Low & $111(8.0)^{\mathrm{b}}$ & $144(9.5)$ & $40(21.6)^{a}$ & $100(13.8)$ & $83(20.0)^{a}$ & $478(11.3)$ & & \\
\hline Moderate & $486(34.8)^{b}$ & $622(41.0)$ & $86(46.5)$ & $291(40.1)$ & $184(44.4)$ & $1,669(39.4)$ & & \\
\hline High & $795(56.9)^{a}$ & $741(48.9)$ & $58(31.4)^{b}$ & $332(45.7)$ & $145(35.0)^{b}$ & $2,071(48.9)$ & & \\
\hline Prevalence & $1,396(32.9)$ & $1,516(35.8)$ & $185(4.4)$ & $726(17.1)$ & $414(9.8)$ & 4,237 (100.0) & & \\
\hline SBQ (T2) & Class $1 n$ (\%) & Class $2 n(\%)$ & Class $3 n(\%)$ & Class $4 n(\%)$ & Class $5 n(\%)$ & Total $n(\%)$ & $d f$ & $F ; p$ (age) $\chi^{2} ; p$ (others) \\
\hline Age (child) (M, SD) & $36.71(2.59)$ & $36.44(2.62)^{*}$ & $36.66(2.69)$ & $36.91(2.64)$ & $36.77(2.66)$ & $36.64(2.63)$ & 4,4220 & $4.62 ; 0.001$ \\
\hline Sex (child) & & & & & & & 4 & $16.76 ; 0.002$ \\
\hline Boys & $642(48.3)$ & $827(53.2)$ & $225(57.1)$ & $351(48.3)$ & $131(56.0)$ & $2,176(51.4)$ & & \\
\hline Girls & $686(51.7)$ & $728(46.8)$ & $169(42.9)$ & $375(51.7)$ & $103(44.0)$ & $2,061(48.6)$ & & \\
\hline Nationality (child) & & & & & & & 8 & $72.53 ;<0.001$ \\
\hline Dutch & $1,282(96.5)^{\mathrm{a}}$ & $1,478(95.0)$ & $354(89.8)^{b}$ & 696 (95.9) & $203(86.8)^{b}$ & $4,013(94.7)$ & & \\
\hline Non-Dutch & $40(3.0)^{b}$ & $71(4.6)$ & $40(10.2)^{a}$ & $29(4.0)$ & $31(13.2)^{a}$ & $211(5.0)$ & & \\
\hline SES (parents) & & & & & & & 12 & $247.67 ;<0.001$ \\
\hline Low & $94(7.1)^{b}$ & $140(9.0)^{b}$ & $93(23.6)^{a}$ & $97(13.4)$ & $54(23.1)^{\mathrm{a}}$ & $478(11.3)$ & & \\
\hline Moderate & $425(32.0)^{b}$ & $615(39.5)$ & $180(45.7)$ & $341(47.0)^{a}$ & $108(46.2)$ & $1,669(39.4)$ & & \\
\hline High & $803(60.5)^{a}$ & $791(50.9)$ & $118(29.9)^{b}$ & $287(39.5)^{b}$ & $72(30.8)^{b}$ & $2,071(48.9)$ & & \\
\hline Prevalence & $1,328(31.4)$ & $1,555(36.7)$ & $394(9.3)$ & $726(17.1)$ & $234(5.5)$ & 4,237 (100.0) & & \\
\hline
\end{tabular}

Note. Percentages of demographic characteristics are given for each individual class, so that the total amounts to (approximately) 100 vertically. However, percentages regarding prevalence add up to 100 horizontally.

*USQ: Children in class 4 were significantly younger than children in classes 1,2 , and $5(p<0.001)$.

SBQ: Children in class 2 were significantly younger than children in class $4(p<0.001)$.

Adjusted residuals revealed significant differences in percentages of children in classes on variables sex, nationality, and SES ( $p<0.001$ ).

${ }^{a}$ Percentage was significantly higher than the overall average percentage.

${ }^{b}$ Percentage was significantly lower than the overall average percentage.

a high SES (60.5\%), compared to the total mean. In contrast, classes 3 and 5 contained a higher proportion of children with a non-Dutch nationality $(10.2 \%$ and $13.2 \%$ respectively) than average. In classes 3,4 , and 5 , children from high SES backgrounds were underrepresented (29.9\%, 39.5\%, and $30.8 \%$ respectively). See Table 4 .

Results of FMM are presented in a line chart with continuous weighted factor scores for each class separately (Figure 2). No other parameters were estimated across classes, thus the class division was solely based on these factor scores. A higher score indicated that toddlers lacked more competences or showed more problems. Globally, three groups could be distinguished, namely one group (classes 1,2, and 4) consisting of relatively normal children, one group (class 3) consisting of children with communication and/or social interaction problems, and one group (class 5) consisting of children with negative and demanding behaviour. The five classes and profiles showed both quantitative and qualitative differences. Class 1 had relatively low scores on all factors and was considered the reference group with typical children. Class 2 was normal in most respects, but showed mild negative behaviour. Scores on negative emotionality and ADHD problems were higher, but scores on demanding behaviour were lower than those of class 1 . Class 4 had mild communication and interaction problems and showed deviant play behaviour, but was otherwise normal. Class 3 was characterized by moderate scores on negative emotionality and ADHD problems, and high scores on language problems and factors involving communication and social interaction, findings suggestive of a wide variety of developmental problems. Class 5 was especially characterized 
Table 5 Weighted factor scores (wfs; proportions) and Cohen's $d$ values of USQ and SBQ factors $(N=4,237)$

\begin{tabular}{|c|c|c|c|c|c|c|c|c|c|c|c|}
\hline \multirow{3}{*}{ Factors USQ (T1) } & \multirow{2}{*}{\multicolumn{2}{|c|}{$\begin{array}{l}\text { Class } 1 \\
32.9 \%\end{array}$}} & \multirow{2}{*}{\multicolumn{2}{|c|}{$\begin{array}{c}\text { Class } 2 \\
35.8 \%\end{array}$}} & \multirow{2}{*}{\multicolumn{2}{|c|}{$\begin{array}{c}\text { Class } 3 \\
4.4 \%\end{array}$}} & \multirow{2}{*}{\multicolumn{2}{|c|}{$\begin{array}{c}\text { Class } 4 \\
17.1 \%\end{array}$}} & \multirow{2}{*}{\multicolumn{2}{|c|}{$\begin{array}{c}\text { Class } 5 \\
9.8 \%\end{array}$}} & \multirow{3}{*}{$F(4,4232) ; p^{\#}$} \\
\hline & & & & & & & & & & & \\
\hline & wfs & $d$ & wfs & $d$ & wfs & $d$ & wfs & $d$ & wfs & $d$ & \\
\hline 1 Deviant communication & 0.06 & 0.00 & 0.09 & 0.36 & 0.40 & $2.49^{* *}$ & 0.31 & $2.12^{* *}$ & 0.13 & 0.69 & $962.86 ;<0.001$ \\
\hline 2 Negative emotionality & 0.08 & 0.00 & 0.23 & $2.43^{* *}$ & 0.30 & $2.80^{* *}$ & 0.10 & 0.43 & 0.45 & $4.67^{* *}$ & $2,904.45 ;<0.001$ \\
\hline 3 Deviant reactive behaviour & 0.00 & 0.00 & 0.00 & -0.04 & 0.00 & 0.08 & 0.00 & 0.02 & 0.00 & 0.10 & $3.68 ;<0.001$ \\
\hline 4 Deviant play behaviour & 0.00 & 0.00 & 0.00 & 0.13 & 0.06 & 0.57 & 0.02 & 0.30 & 0.01 & 0.29 & $55.35 ;<0.001$ \\
\hline 5 Demanding behaviour & 0.27 & 0.00 & 0.22 & -0.27 & 0.32 & 0.23 & 0.30 & 0.20 & 0.54 & $1.08^{*}$ & $203.11 ;<0.001$ \\
\hline 6 Social anxiety/inhibition & 0.07 & 0.00 & 0.10 & 0.25 & 0.14 & 0.52 & 0.07 & 0.07 & 0.17 & 0.69 & $53.27 ;<0.001$ \\
\hline 7 Advanced social interaction problems & 0.04 & 0.00 & 0.06 & 0.40 & 0.25 & $2.04^{* *}$ & 0.14 & $1.30^{*}$ & 0.09 & $0.81^{*}$ & $527.95 ;<0.001$ \\
\hline 8 Basic social interaction problems & 0.01 & 0.00 & 0.03 & 0.30 & 0.11 & 0.77 & 0.03 & 0.34 & 0.07 & 0.67 & $88.53 ;<0.001$ \\
\hline \multirow[t]{2}{*}{9 Sleep problems } & 0.10 & 0.00 & 0.16 & 0.38 & 0.26 & $0.90^{*}$ & 0.13 & 0.22 & 0.30 & $1.14^{*}$ & $138.49 ;<0.001$ \\
\hline & \multicolumn{2}{|c|}{ Class 1} & \multicolumn{2}{|c|}{ Class 2} & \multicolumn{2}{|c|}{ Class 3} & \multicolumn{2}{|c|}{ Class 4} & \multicolumn{2}{|c|}{ Class 5} & \\
\hline \multirow[t]{2}{*}{ Factors SBQ (T2) } & \multicolumn{2}{|c|}{$31.4 \%$} & \multicolumn{2}{|c|}{$36.7 \%$} & \multicolumn{2}{|c|}{$9.3 \%$} & \multicolumn{2}{|c|}{$17.1 \%$} & \multicolumn{2}{|c|}{$5.5 \%$} & $F(4,4232) ; p^{\#}$ \\
\hline & wfs & $d$ & wfs & $d$ & wfs & $d$ & wfs & $d$ & wfs & $d$ & \\
\hline 1 Language problems & 0.03 & 0.00 & 0.04 & 0.19 & 0.29 & $1.39^{* *}$ & 0.10 & 0.62 & 0.13 & 0.69 & $351.52 ;<0.001$ \\
\hline 2 Negative emotionality & 0.06 & 0.00 & 0.22 & $2.39^{* *}$ & 0.26 & $2.50^{* *}$ & 0.08 & 0.44 & 0.44 & $4.03^{* *}$ & $2,087.01 ;<0.001$ \\
\hline 3 Attention-deficit/hyperactivity problems & 0.06 & 0.00 & 0.21 & $0.97^{*}$ & 0.34 & $1.59^{* *}$ & 0.11 & 0.37 & 0.47 & $2.00^{* *}$ & 451,$86 ;<0.001$ \\
\hline 4 Deviant play behaviour & 0.01 & 0.00 & 0.03 & 0.29 & 0.21 & $1.27^{*}$ & 0.13 & $0.95^{*}$ & 0.10 & 0.77 & $313.50 ;<0.001$ \\
\hline 5 Demanding behaviour & 0.33 & 0.00 & 0.19 & $-0.99^{*}$ & 0.24 & -0.63 & 0.31 & -0.17 & 0.71 & $2.42^{* *}$ & $680.53 ;<0.001$ \\
\hline 6 Deviant affective behaviour & 0.00 & 0.00 & 0.01 & 0.27 & 0.13 & $1.07^{*}$ & 0.04 & 0.61 & 0.07 & $0.81^{*}$ & $263.49 ;<0.001$ \\
\hline 7 Communication and interaction problems & 0.04 & 0.00 & 0.06 & 0.67 & 0.24 & $2.41^{* *}$ & 0.15 & $2.20^{* *}$ & 0.13 & $1.32^{* *}$ & $1,188.02 ;<0.001$ \\
\hline 8 Sleep problems & 0.10 & 0.00 & 0.21 & 0.44 & 0.24 & 0.53 & 0.10 & -0.03 & 0.34 & $0.84^{*}$ & $86.07 ;<0.001$ \\
\hline
\end{tabular}

\#The weighted factor score is the obtained factor sum score divided by the maximum factor sum score, and has a value between 0 and 1 . Higher scores indicated that children lacked more competences or showed more problems. Most differences in weighted factor scores between classes were significant $(p<0.001)$. However, the following contrasts were not significantly different: USQ: factor 3 classes 1, 2, 3, 4, and 5; factor 4 classes 1 and 2, classes 2 and 5, classes 4 and 5 ; factor 5 classes 1, 3, and 4; factor 6 classes 1, 2, and 4, classes 3 and 5; factor 8 classes 2 and 4; factor 9 classes 3 and 5. SBQ: factor 1 classes 1 and 2, classes 4 and 5; factor 4 classes 4 and 5; factor 5 classes 1 and 4; factor 6 classes 1 and 2; factor 8 classes 1 and 4, classes 2 and 3 .

Cohen's $d$ : comparison between the weighted factor score of class 1 versus classes $2,3,4$, and 5 ; * large effect size $(d \geq 0.80) ;{ }^{*}$ very large effect size $(d \geq 1.30)$.

by high scores on negative emotionality, ADHD problems, and demanding behaviour. These children seemed to be at comparatively high risk for externalizing problems.

For each separate factor, the continuous weighted factor scores of all five classes were compared with each other. One-way ANOVA and Bonferroni corrected post hoc tests revealed that all but seven differences were significant $(p<0.001)$. Several (very) large effect sizes, expressed in Cohen's $d$, were found between class 1 on the one hand and classes 2, 3, 4, and 5 on the other. Classes 3 and 5 stood out because the weighted factor scores of six of the eight factors were significantly higher than those of class 1 . See also Table 5. Analyses were repeated with inclusion of covariate sex in the model, which did not reveal significantly different levels of problems between boys and girls. There were no other covariance parameters included.

\section{Longitudinal stability of factors and classes}

Item scores with values 0,1 , and 2 were used to compute weighted factor scores. Obtained factor sum scores were divided by maximum factor sum scores, what resulted in continuous weighted factor scores with values between 0 and 1.

Most correlations between the factors at age 14-15 months and at age 36-37 months were small, but significant $(p \leq 0.001)$. See Table 6 . The highest correlations were found between factors with overlapping or similar items: deviant communication (USQ) and language problems (SBQ) $(r=0.35)$; negative emotionality (USQ) and negative emotionality and attention-deficit/hyperactivity problems (SBQ) ( $r=0.44$ and $r=0.32$, respectively); advanced social interaction problems (USQ) and communication and interaction problems (SBQ) $(r=0.34)$; sleep problems (USQ) and sleep problems (SBQ) $(r=0.31)$.

At age 36-37 months, the profiles showed more variation in the type of behaviour and behaviour seemed to be more crystallized, especially in classes 3 and 5, compared to the profiles at age 14-15 months. The proportion of children with normal behaviour (class 1) was similar at T1 and T2 (32.9\% versus $31.4 \%)$, but there were more children with mild problems (classes 2 and $453.8 \%$ ) at T2 

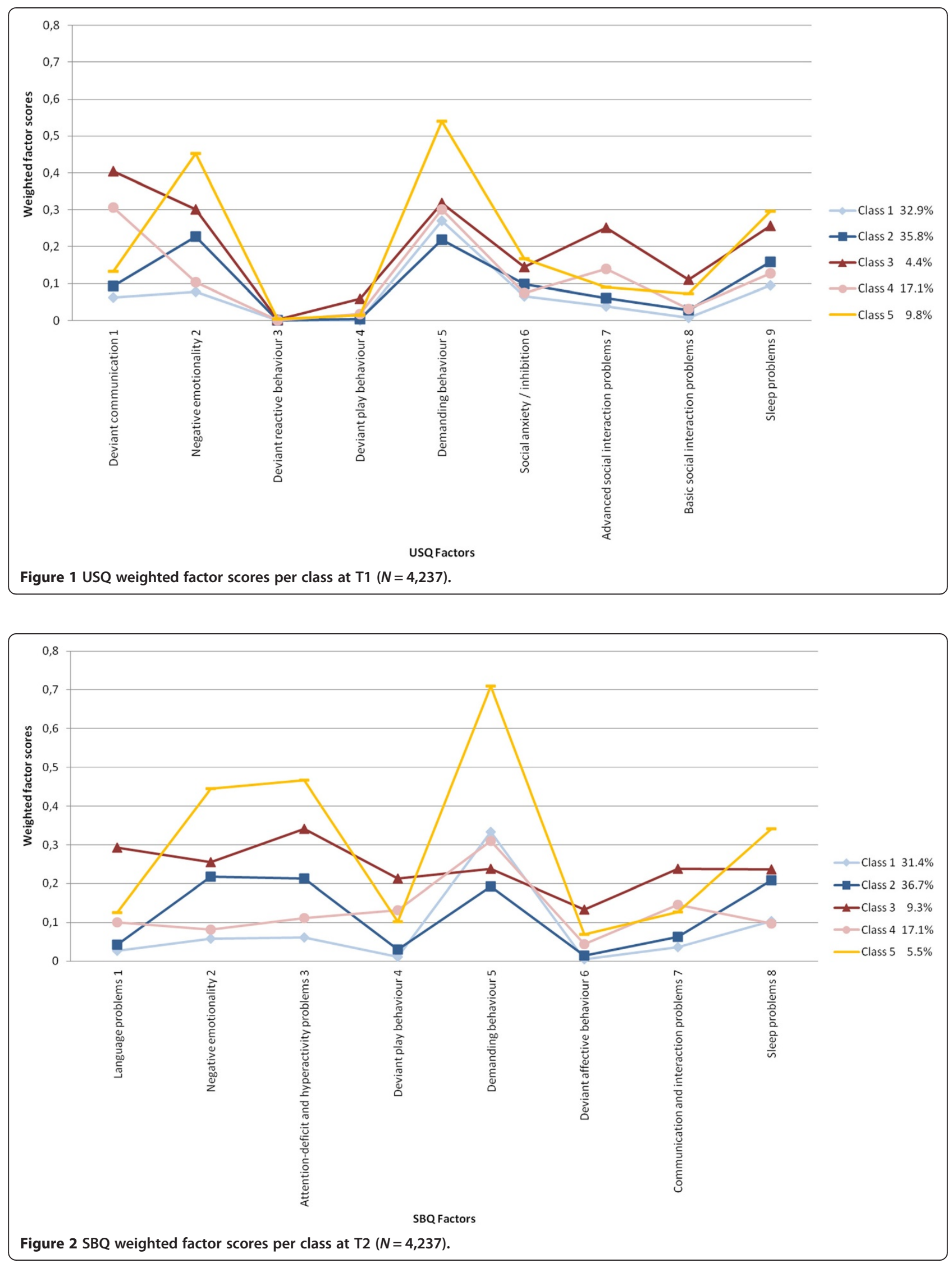
Table 6 Pearson correlation matrix of USQ and SBQ factors $(N=4,237)$

\begin{tabular}{|c|c|c|c|c|c|c|c|c|}
\hline \multirow[b]{2}{*}{ Factors USQ (T1) } & \multicolumn{8}{|c|}{ Factors SBQ (T2) } \\
\hline & $\begin{array}{l}1 \text { Language } \\
\text { problems }\end{array}$ & $\begin{array}{l}2 \text { Negative } \\
\text { emotionality }\end{array}$ & $\begin{array}{l}3 \text { ADHD- } \\
\text { problems }\end{array}$ & $\begin{array}{c}4 \text { Deviant } \\
\text { play behaviour }\end{array}$ & $\begin{array}{l}5 \text { Demanding } \\
\text { behaviour }\end{array}$ & $\begin{array}{l}6 \text { Deviant } \\
\text { affective } \\
\text { behaviour }\end{array}$ & $\begin{array}{l}7 \text { Com. } \\
\text { interact. } \\
\text { problems }\end{array}$ & $\begin{array}{l}8 \text { Sleep } \\
\text { problems }\end{array}$ \\
\hline 1 Deviant communication & $0.35^{*}$ & $0.09^{*}$ & $0.10^{*}$ & $0.15^{*}$ & 0.05 & $0.17^{*}$ & $0.25^{*}$ & -0.00 \\
\hline 2 Negative emotionality & $0.07^{*}$ & $0.44^{*}$ & $0.32^{*}$ & $0.12^{*}$ & $0.07^{*}$ & $0.11^{*}$ & $0.14^{*}$ & $0.15^{*}$ \\
\hline 3 Deviant reactive behaviour & 0.00 & 0.02 & -0.01 & $0.05^{*}$ & 0.00 & 0.03 & 0.02 & 0.01 \\
\hline 4 Deviant play behaviour & $0.12^{*}$ & 0.04 & $0.08^{*}$ & $0.11^{*}$ & 0.04 & $0.10^{*}$ & $0.14^{*}$ & -0.02 \\
\hline 5 Demanding behaviour & 0.04 & $0.10^{*}$ & $0.10^{*}$ & 0.03 & $0.19^{*}$ & 0.04 & $0.05^{*}$ & 0.04 \\
\hline 6 Social anxiety/inhibition & $0.05^{*}$ & $0.12^{*}$ & $0.05^{*}$ & $0.06^{*}$ & 0.03 & $0.05^{*}$ & 0.04 & $0.07^{*}$ \\
\hline 7 Advanced social interaction problems & $0.23^{*}$ & $0.09^{*}$ & $0.13^{*}$ & $0.23^{*}$ & 0.03 & $0.19^{*}$ & $0.34^{*}$ & 0.02 \\
\hline 8 Basic social interaction problems & $0.14^{*}$ & $0.19^{*}$ & $0.20^{*}$ & $0.15^{*}$ & $0.06^{*}$ & $0.13^{*}$ & $0.22^{*}$ & $0.09^{*}$ \\
\hline 9 Sleep problems & $0.06^{*}$ & $0.17^{*}$ & $0.12^{*}$ & $0.09^{*}$ & $0.06^{*}$ & $0.09^{*}$ & $0.13^{*}$ & 0.31 \\
\hline
\end{tabular}

*Most correlations $(r)$ were small, but significant $(p \leq 0.001)$. The highest correlations were found between deviant communication (USQ) and language problems (SBQ); negative emotionality (USQ) and negative emotionality / attention-deficit/hyperactivity problems (SBQ); advanced social interaction problems (USQ) and communication and interaction problems (SBQ); sleep problems (USQ) and sleep problems (SBQ).

than at T1 (class 2 35.8\%). Some children had moderate problems (class $4.17 .1 \%$ ) at $\mathrm{T} 1$, but this type of problem was no longer seen at T2. The proportion of children with severe problems was about the same at T1 and T2 $(14.2 \%$ versus $14.8 \%$ ). The proportion of children with communication and interaction problems (class 3 ) or with negative and demanding behaviour (class 5) was reversed at T1 (4.4\% and $9.8 \%$, respectively) and $\mathrm{T} 2(9.3 \%$ and $5.5 \%$, respectively).

Crosstabs were calculated to examine significant changes in behavioural profiles over time. Transitions that affected more than $10 \%$ of the children and that had adjusted residuals of 2 or higher $(p=0.05)$ (i.e. difference between observed and expected frequency divided by an estimate of its standard deviation) are reported (Figure 3). There were five main findings. First, children who showed normal or near normal behaviour (classes 1 and 2) at T1 had similar behaviour (classes 1, 2, and 4) at T2 (green arrows), thus children with near normal behaviour in infancy did not develop deviant behaviour in toddlerhood. Second, the majority (85\%) of children with moderate communication problems (class 4) at T1 showed normal behaviour (or with only mild problems) (classes 1, 2, and 4) at T2 (orange arrows); however, some children (15\%) had severe problems at T2, especially communication and interaction problems (class 3) (red arrow). Third, children with severe problems (classes 3 and 5) at T1 did not have completely normal behaviour (class 1) at T2; however, the behaviour of a substantial proportion of children with severe problems (44.9\% of class 3 and $52.9 \%$ of class 5) improved to near normal behaviour (classes 2 and 4) (orange arrows). Fourth, negative and demanding behaviour tended to improve over time more $(62.3 \%$ of the children from class 5 at T1 shifted to classes 1,2 , and 4 at T2) than did communication and interaction problems
(51.9\% of the children from class 3 at $\mathrm{T} 1$ shifted to classes 1,2 , and 4 at T2). Fifth, homotypic continuity occurred more often than heterotypic continuity in children with communication and interaction problems (35.7\% homotypic versus $12.4 \%$ heterotypic (from class 3 at T1 to class 3 and 5 at T2, respectively)) than in children with negative and demanding behaviour (21.0\% homotypic versus $16.7 \%$ heterotypic (from class 5 at T1 to classes 5 and 3 at T2, respectively)) (red arrows).

\section{Representativeness of follow-up sample}

At T2 $(N=4,237)$ the sample was smaller than at $\mathrm{T} 1$ $(N=6,330)$; the follow-up rate was $66.9 \%$. We checked for selective attrition and found follow-up rates to be different by demographic data $(p<0.001)$. The follow-up rate was lower for children with a Moroccan or Turkish nationality than for Dutch children (33.8\% versus 69.9\%). The follow-up rates of children with European and other nationalities were in between. Regarding the SES as well as the level of education and occupation can be concluded that the follow-up rate was lowest for the children of parents with a low level (about 60\%) and highest for the parents with a high level (about 70\%). The follow-up rate for boys and girls was $67.9 \%$ and $68.2 \%$ respectively $(p=0.78)$. The follow-up rates for children in the different behavioural classes were: class $170.6 \%$, class $266.7 \%$, class $350.8 \%$, class 4 69.9\%, and class 5 60.5\% ( $p<0.001)$. As expected, the follow-up rate was lowest for children with communication and interaction problems (class 3 ) and for children with negative and demanding behaviour (class 5). Independent samples T-tests comparing the weighted factor scores of children in class 3 at $\mathrm{T} 1$ revealed that drop-outs scored significantly higher on social anxiety/ inhibition $(p=0.002)$, advanced social interaction problems $(p<0.001)$, and sleep problems $(p=0.002)$ than follow-ups. 


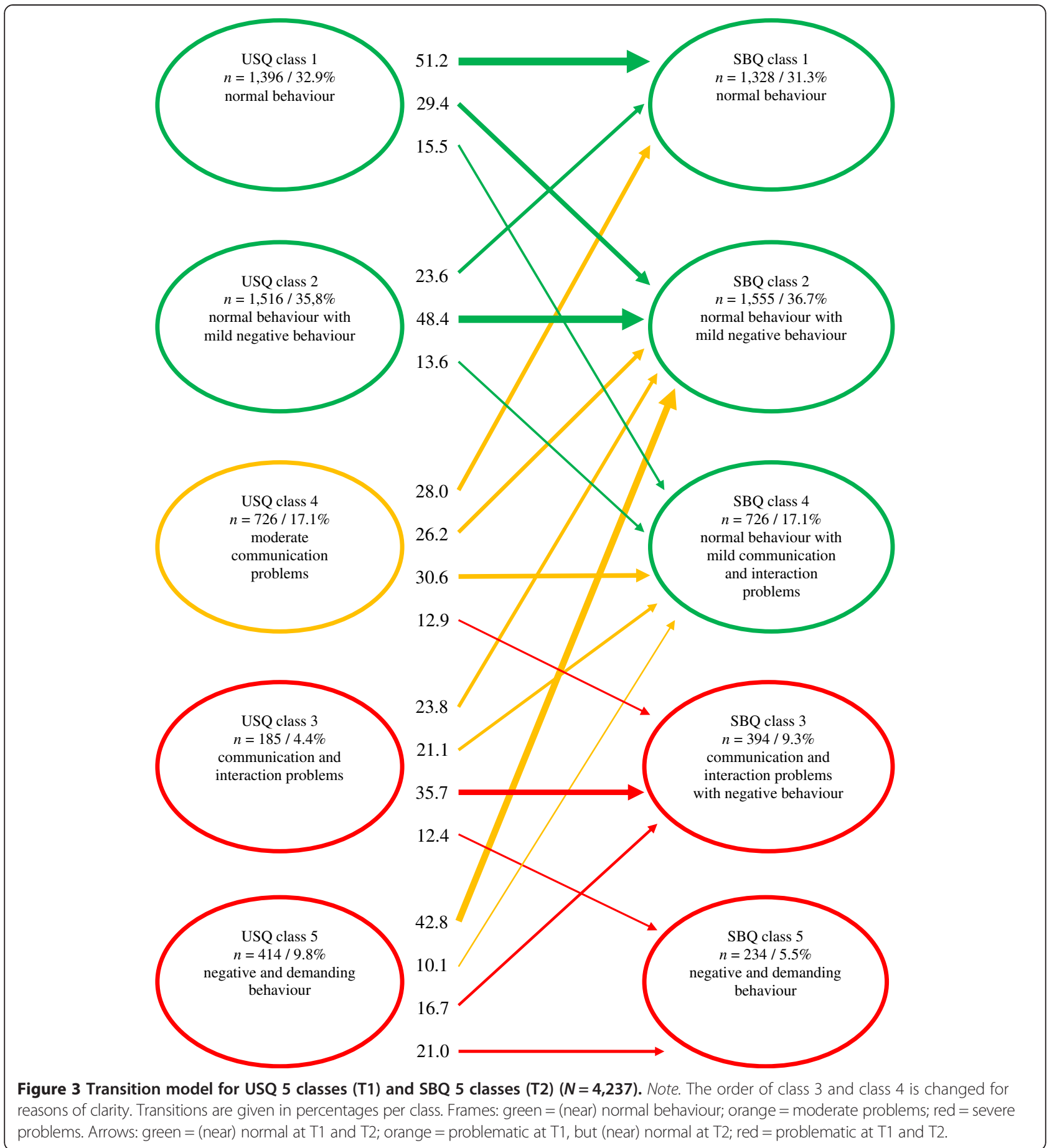

The higher symptom severity at $\mathrm{T} 1$ of drop-outs suggests that the proportion of children with persistent communication and interaction problems at T2 was underestimated. At T1, children of class 5 who dropped out had slightly more advanced social interaction problems $(p=0.02)$ and sleep problems $(p=0.03)$ than those who completed the follow-up. Differences on other factors were not significant, in particular not on negative emotionality $(p=0.71)$, which factor included items most characteristic for negative and demanding behaviour, suggesting that overall follow-ups at T2 were representative of class 5 .

\section{Discussion}

We explored the course of a small number of parentreported problem behaviours in a large longitudinal 
population-based sample of Dutch children from age 14-15 months (T1) to age 36-37 months (T2). While negative emotionality, demanding behaviour, deviant play behaviour, and sleep problems tended to group similarly at both time points, deviant communication, social anxiety/inhibition, as well as basic and advanced social interaction problems at $\mathrm{T} 1$ were combined in one factor termed communication and interaction problems at T2. As expected, language problems was identified as a new factor in toddlerhood. The changes are partly due to a decrease in the number of participants (from 6,330 infants at $\mathrm{T} 1$ to 4,237 toddlers at $\mathrm{T} 2$ ) and a reduction in the number of items (from 74 items in USQ to 62 items in SBQ). These can be considered as measurement effects. Besides, developmental effects also played a role.

The proportion of children with normal behaviour or mild negative behaviour was similar at both ages (nearly $70 \%$ ), and no children with normal behaviour at 14-15 months had deviant behaviour at 36-37 months. Most infants $(84.8 \%)$ with moderate communication problems showed near normal behaviour in toddlerhood. However, communication and interaction problems as well as negative and demanding behaviour in infancy were strong predictors of mild to severe problems in toddlerhood, as no infants with these problems showed completely normal behaviour as toddlers. However, $62.3 \%$ of infants with negative and demanding behaviour showed behavioural improvement in toddlerhood, compared with $51.9 \%$ of infants with communication and interaction problems. In addition, homotypic continuity was less pronounced for negative and demanding behaviour (21.0\% homotypic versus $16.7 \%$ heterotypic) than for communication and interaction problems (35.7\% homotypic versus $12.4 \%$ heterotypic). The proportion of children with negative and demanding behaviour decreased, but their behaviour problems became more severe. In contrast, communication and interaction problems affected more children and were often seen in combination with language problems and moderate negative behaviour. Thus, negative and demanding behaviour would appear to be transient more often and a less specific predictor of problems in toddlerhood than communication and interaction problems.

Our research has several scientific and clinical implications. Forty percent of the toddlers with communication and interaction problems had these problems as infants, a finding consistent with the results of a large screening study of early symptoms of ASD in the general population $[26,27]$. At the same time, however, about $40 \%$ of the children with communication and interaction problems in toddlerhood were not identified and reported correctly by their parents in infancy, possibly because the symptoms were less obvious and severe, or because the parents were not able or willing to recognize them properly. Therefore, it is essential to improve the methods and instruments for the identification of more subtle symptoms of infants, in addition to a repeated screening and evaluation of communication and interaction problems of toddlers. Our data regarding communication and interaction problems are not very fine grained and do not include information about regressive behaviours. Consequently, they suggest only two patterns of ASD onset: a very early onset and a somewhat later onset. However, these different trajectories partly correspond with the results of smaller but more detailed studies of the early development of clinically referred children with communication and interaction problems, i.e. children with ASD. Ozonoff et al. [32] identified three patterns of onset of ASD: early onset, regression, and plateau. More research is needed, bearing in mind that symptom emergence can be considered as a continuum of many phenotypes containing different characteristics and varying in severity [5,32,33].

Although negative and demanding behaviour may be transient in many children, it may be persistent in some others and can lead to serious child psychiatric disorders, such as ADHD. According to Sonuga-Barke and Halperin [4], the onset of ADHD is best described through syndrome trajectories that allow fluctuations over time (emergence, persistence, decrease, increase) depending on the child's chronological and developmental age. Willoughby, Pek, and Greenberg [34] distinguished three main patterns of ADHD symptoms, namely, consistently low, remittent, and persistently high, in a population-based sample of preschoolers. In our research, behaviour improved in a substantial proportion of children (at least 40\%). Though, it remains to be seen whether this improvement is permanent, or whether negative and demanding behaviour re-emerges in childhood. However, in about $20 \%$ of the children, externalizing problems were present in both infancy and toddlerhood, and may remain throughout childhood and later adolescence. These children may form a group with persistent externalizing problems, who may benefit from early intervention.

Thus, various trajectories of ASD on the one hand and $\mathrm{ADHD}$ on the other hand can be distinguished. However, severe communication and social interaction problems may also occur in combination with persistent externalizing behaviour. Both conditions may reinforce each other, may complicate development, and may influence functioning [35]. ASD and ADHD may share genetic and environmental risk factors, developmental pathways, as well as cognitive and neural mechanisms [36,37]. It has even been suggested that the two conditions represent different manifestations of a common underlying disorder [38]. Our findings provide a context to examine the shared and unique behavioural precursors of ASD and ADHD.

Albeit the study was carried out in a large populationbased sample, it had some limitations. The T2 sample comprised 4,237 children, only $34.5 \%$ of the total sample 
$(N=12,297)$. The T2 sample mainly consisted of children of Dutch parents with a relatively high educational level and a high SES. This means that our findings are not automatically applicable to other children (and parents), i.e. from other nationalities, with lower educational levels, and/or with lower SES. We suppose that higher educated/SES parents generally may be more aware of typical development and behaviour, and changes or deviations therein. Probably, they may better understand the importance of screening and research, and may also be more inclined to search for help than lower educated/ SES parents. However, these assumptions should be tested to make reliable statements. The chance to develop deviant behaviour is influenced by predisposing factors, like genetic constitution, problems during pregnancy or birth, developmental delays or psychiatric disorders in siblings and parents. Regrettably, information about such factors was not available, hence it was not possible to investigate the role of these factors on the children's behaviour. Unfortunately, only one parent report per child was available and information from additional sources was lacking, because the children were not clinically assessed. At this young age parents are important persons to signal problems in their children, both in the general population and in clinical samples $[6,12,16,19]$. However, parental incidental observations and reports are not as accurate and effective as professional standardized procedures and measurements to indentify children's symptoms. Above that, parents and professionals seem to detect different aspects of abnormal behaviour $[39,40]$. Thus, it is desirable to incorporate observations, measurements, and reports of both informants to increase the sensitivity and specificity in future research.

The behavioural classes identified in this study were based on statistical analyses of parent reports, and not on theoretical knowledge and/or clinical experience. We assumed that the children in classes 1,2 , and 4 had relatively normal behaviour, whereas the children in the other classes showed deviant behaviour in some aspects. However, there appears to be a grey area between normal and deviant behaviour. Based on class prevalence at both time points, one could have referred to class 2 as the normal class instead of class 1 . The lively and mild negative behaviour of class 2 could have been considered as developmentally typical, whereas the quiet and obedient behaviour of class 1 could have been interpreted as slightly different. Further research may shed more light on the exact type and cause of these variations. Strict factorial invariance, and thus configural (measurement) invariance, is needed for comparisons of factor scores between classes [10]. Because we did not specifically test for it, one should be cautious when comparing factor scores across classes at the same time point. However, invariance seems to be of minor importance and influence when comparing classes over a certain time span as is done in the transition model.

We used FMM to determine factors and classes at two time points and we established the transition model afterwards in a separate step. If one was only interested in the division of children into homogeneous groups and the transitions over time, latent transition analysis (LTA), in which the computation of classes and transitions is integrated into one model, may have been an adequate alternative. However, if one preferred a complete picture of both factors and classes, then FMM would have been more appropriate. The factors point in the direction of certain types of behaviour and/or child psychiatric disorders of various groups of children. Depicting the division of and the mutual relations between classes at several time points gives insight in longitudinal transitions. Careful predictions about chances of improvement and risks of problems in the transition from infancy to toddlerhood can only be made for groups of children and not for individual cases. At the group level, there was no significant transition from completely normal behaviour to deviant behaviour and vice versa. Nevertheless, such changes may have occurred in some children. This is of minor relevance in epidemiological research, but of major importance in clinical practice. The normalization of behaviour in children with severe problems may have been overestimated, because there was selective attrition of the two most impaired classes, a commonly observed phenomenon in this type of research [41]. However, this only further underlines the persistence of behavioural difficulties from infancy to a later age.

\section{Conclusion}

The results suggest that certain problems may persist from infancy to toddlerhood, while others may change into other problem behaviour or may disappear. Profound communication and interaction problems as well as negative and demanding behaviour in infancy often result in mild to severe problems in toddlerhood, with the former being least transient and the most specific predictor. More research is necessary to determine the relationship between behavioural problems in the classes identified and in clinical diagnoses.

\footnotetext{
Abbreviations

ADHD: Attention-deficit/hyperactivity disorder; ANOVA: Analysis of variance; ASD: Autism spectrum disorder; DC 0-3R: Diagnostic Classification of mental health and developmental disorders of infancy and early childhood, revised edition; DSM-IV-TR: Diagnostic and Statistical Manual of mental disorders, fourth edition, text revision; EFA: Exploratory factor analysis; ERV: Estimated residual variance; ESAT: Early Screening of Autistic Traits Questionnaire; FMM: Factor mixture modelling; ICD-10: International Statistical Classification of Diseases and related health problems, tenth revision; LCA: Latent class analysis; LMR adj. LRT: Lo-Mendell-Rubin adjusted likelihood ratio test; ODD: Oppositional defiant disorder; RMSR: Root mean square residual; SBQ: Social Behaviour Questionnaire; SES: Socioeconomic status; (SSA) BIC: (Sample-size adjusted) Bayesian information criterion; USQ: Utrecht
} 
Screening Questionnaire; VLMR LRT: Vuong-Lo-Mendell-Rubin likelihood ratio test.

\section{Competing interests}

In the past five years, Jan K. Buitelaar has been a consultant, advisory board member, and/or speaker for Janssen Cilag BV, Eli Lilly, Organon/Shering Plough, UCB, Shire, Medice, and Servier. He is not an employee or a stock shareholder of any of these companies. He has no other financial or material support, including expert testimony, patents, and royalties. The other authors declare that they have no competing interests.

\section{Authors' contributions}

EM was responsible for collecting and analysing the data as well as writing the manuscript. ML performed statistical analyses, interpreted data, and commented on drafts. SS designed and coordinated the study and supervised the data collection. NL and JB reviewed and edited subsequent drafts. All authors read and approved the final manuscript.

\section{Acknowledgements}

This research is part of the SOSO project which is financially supported by the Dutch Organization for Scientific Research (ZonMw CZ-TT 940-38-045 Research Program Chronic Diseases) and by University Medical Centre Utrecht, Radboud University Nijmegen Medical Centre, and Karakter University Centre Nijmegen, The Netherlands. We are very grateful to the parents who filled out the questionnaires about their child's behaviour.

\section{Author details}

${ }^{1}$ Department of Psychiatry, Nijmegen Centre for Evidence-Based Practice, Radboud University Nijmegen Medical Centre, P.O. Box 9101, 6500 HB Nijmegen, The Netherlands. ${ }^{2}$ Department of Cognitive Neuroscience, Donders Institute for Brain, Cognition and Behaviour, Radboud University Nijmegen Medical Centre, P. O. Box 9104, 6500 HE Nijmegen, The Netherlands. ${ }^{3}$ Karakter Child and Adolescent Psychiatry University Centre, Reinier Postlaan 12, 6525 GC Nijmegen, The Netherlands.

Received: 10 November 2013 Accepted: 25 June 2014 Published: 7 July 2014

\section{References}

1. American Psychiatric Association: Diagnostic and Statistical Manual of Mental Disorders, 4th edition, text revision. Washington, DC: APA; 2000.

2. World Health Organization: International Statistical Classification of Diseases and Related Health Problems. 10th edition. Geneva, Switzerland: WHO; 1992

3. Egger $\mathrm{HL}$, Angold A: Common emotional and behavioural disorders in preschool children: presentation, nosology, and epidemiology. J Child Psychol Psychiatry 2006, 47:313-337.

4. Sonuga-Barke EJ, Halperin JM: Developmental phenotypes and causal pathways in attention deficit/hyperactivity disorder: potential targets for early intervention? J Child Psychol Psychiatry 2010, 51:368-389.

5. Yirmiya N, Charman T: The prodrome of autism: early behavioral and biological signs, regression, peri- and post-natal development and genetics. J Child Psychol Psychiatry 2010, 51:432-458.

6. Skovgaard AM, Houmann T, Landorph SL, Christiansen E: Assessment and classification of psychopathology in epidemiological research of children 0-3 years of age: a review of the literature. Eur Child Adolesc Psychiatry 2004, 13:337-346.

7. Postert C, Averbeck-Holocher M, Beyer T, Müller J, Furniss T: Five systems of psychiatric classification for preschool children: do differences in validity, usefulness and reliability make for competitive or complementary constellations? Child Psychiatry Hum Dev 2009, 40:25-41.

8. Zero to Three: Diagnostic Classification: 0-3R: Diagnostic Classification of Mental Health and Developmental Disorders of Infancy and Early Childhood, Revised edition. Washington, DC: ZT; 2005.

9. Bölte S, Marschik PB, Falck-Ytter T, Charman T, Roeyers H, Elsabbagh M: Infants at risk for autism: a European perspective on current status, challenges and opportunities. Eur Child Adolesc Psychiatry 2013, 22:341-348.

10. Lubke GH, Muthén B: Investigating population heterogeneity with factor mixture models. Psychol Methods 2005, 10:21-29.

11. McCutcheon AL: Latent Class Analysis. Beverly Hills, CA: Sage; 1987.
12. Mathiesen KS, Sanson A: Dimensions of early childhood behavior problems: stability and predictors of change from 18 to 30 months. J Abnorm Child Psychol 2000, 28:15-31.

13. Costello EJ, Mustillo S, Erkanli A, Keeler G, Angold A: Prevalence and development of psychiatric disorders in childhood and adolescence. Arch Gen Psychiatry 2003, 60:837-844.

14. Briggs-Gowan MJ, Carter AS, Bosson-Heenan J, Guyer AE, Horwitz SM: Are infant-toddler social-emotional and behavioral problems transient? J Am Acad Child Adolesc Psychiatry 2006, 45:849-858.

15. Carter AS, Briggs-Gowan MJ, Davis NO: Assessment of young children's social-emotional development and psychopathology: recent advances and recommendations for practice. J Child Psychol Psychiatry 2004, 45:109-134.

16. Mathiesen KS, Sanson A, Stoolmiller M, Karevold E: The nature and predictors of undercontrolled and internalizing problem trajectories across early childhood. J Abnorm Child Psychol 2009, 37:209-222.

17. Bufferd SJ, Dougherty LR, Carlson GA, Rose S, Klein DN: Psychiatric disorders in preschoolers: continuity from ages 3 to 6 . Am J of Psychiatry 2012, 169:1157-1164.

18. Beyer T, Postert C, Müller JM, Furniss T: Prognosis and continuity of child mental health problems from preschool to primary school: results of a four-year longitudinal study. Child Psychiatry Hum Dev 2012, 43:533-543.

19. Angold A, Egger HL: Preschool psychopathology: lessons for the lifespan. J Child Psychol Psychiatry 2007, 48:961-966.

20. Möricke E, Lappenschaar GAM, Swinkels SHN, Rommelse NNJ, Buitelaar JK: Latent class analysis reveals five homogeneous behavioural and developmental profiles in a large Dutch population sample of infants aged 14-15 months. Eur Child Adolesc Psychiatry 2013, 22:103-115.

21. Central Office for Statistics (Centraal Bureau voor Statistiek): Voorburg, The Netherlands: CBS; 2003

22. Beernink AC, Swinkels SHN, Buitelaar JK: Problem behavior in a community sample of 14- and 19-month-old children: common versus uncommon behaviors, structure, and stability. Eur Child Adolesc Psychiatry 2007, 16:271-280

23. Achenbach TM, Rescorla LA: Manual for the ASEBA Preschool Forms \& Profiles. Burlington, VT: University of Vermont, Research Center for Children, Youth, \& Families; 2000

24. Carter AS, Briggs-Gowan MJ: Infant-Toddler Social and Emotional Assessment (ITSEA): Manual. New Haven, CT: Yale University, Department of Psychology; 2000.

25. Sparrow SS, Balla DA, Cicchetti DV: Vineland Social-Emotional Early Childhood Scales: Manual. Circles Pine, MN: American Guidance Service Inc.; 1997.

26. Swinkels SHN, Dietz C, Van Daalen E, Kerkhof IHGM, Van Engeland H, Buitelaar JK: Screening for autistic spectrum in children aged 14 to 15 months. I: the development of the Early Screening of Autistic Traits Questionnaire (ESAT). J Autism Dev Disord 2006, 36:723-732.

27. Dietz C, Swinkels SHN, Van Daalen E, Van Engeland H, Buitelaar JK: Screening for autistic spectrum disorder in children aged 14-15 months. Il: population screening with the Early Screening of Autistic Traits Questionnaire (ESAT). Design and general findings. J Autism Dev Disord 2006, 36:713-722.

28. Donders ART, Van der Heijden GJMG, Stijnen T, Moons KGM: Review: a gentle introduction to imputation of missing values. J Clin Epidemiol 2006, 59:1087-1091.

29. Nylund KL, Asparouhov T, Muthén BO: Deciding on the number of classes in latent class analyses and growth mixture modeling: a Monte Carlo simulation study. Struct Equ Modeling 2007, 14:535-569.

30. Muthén LK, Muthén BO: Mplus User's Guide. Statistical Analysis with Latent Variables, 4th edition; version 4.1. Muthén \& Muthén: Los Angeles, CA; 2006.

31. Statistical Package for Social Sciences: SPSS for Windows, Release 17.0. Chicago, IL: SPSS Inc; 2009.

32. Ozonoff S, losif AM, Young GS, Hepburn S, Thompson M, Colombi C, Cook IC, Werner E, Goldring S, Baguio F, Rogers SJ: Onset patterns in autism: correspondence between home video and parent report. J Am Acad Child Adolesc Psychiatry 2011, 50:796-806.

33. Shumway S, Thurm A, Swedo SE, Deprey L, Barnett LA, Amaral DG, Rogers SJ, Ozonoff S: Brief report: symptom onset patterns and functional outcomes in young children with autism spectrum disorders. J Autism Dev Disord 2011, 41:1727-1732.

34. Willoughby MT, Pek J, Greenberg MT, the Family Life Project Investigators: Parent-reported attention deficit/hyperactivity symptomatology in preschool-aged children: factor structure, developmental change, and early risk factors. J Abnorm Child Psychol 2012, 40:1301-1312. 
35. Rao PA, Landa RJ: Association between severity of behavioural phenotype and comorbid attention deficit hyperactivity disorder symptoms in children with autism spectrum disorders. Autism 2014, 18:272-280.

36. Rommelse NNJ, Franke B, Geurts HM, Hartman CA, Buitelaar JK: Shared heritability of attention-deficit/hyperactivity disorder and autism spectrum disorder. Eur Child Adolesc Psychiatry 2010, 19:281-295.

37. Rommelse NNJ, Geurts HM, Franke B, Buitelaar JK, Hartman CA: A review on cognitive and brain endophenotypes that may be common in autism spectrum disorder and attention-deficit/hyperactivity disorder and facilitate the search for pleiotropic genes. Neurosci Biobehav Rev 2011, 35:1363-1396.

38. Van der Meer JMJ, Oerlemans AM, Van Steijn DJ, Lappenschaar MGA, De Sonneville LMJ, Buitelaar JK, Rommelse NNJ: Are autism spectrum disorder and attention-deficit/hyperactivity disorder different manifestations of one overarching disorder? Cognitive and symptom evidence from a clinical and population-based sample. J Am Acad Child Adolesc Psychiatry 2012, 51:1160-1172.

39. Stone WL, Hoffman EL, Lewis SE, Ousley OY: Early recognition of autism. Parental reports vs clinical observation. Arch Pediatr Adolesc Med 1994, 148:174-179.

40. Zwaigenbaum L, Bryson S, Rogers T, Roberts W, Brian J, Szatmari P: Behavioral manifestations of autism in the first year of life. Int J Devl Neurosci 2005, 23:143-152.

41. Wolke D, Waylen A, Samara M, Steer C, Goodman R, Ford T, Lamberts K: Selective drop-out in longitudinal studies and non-biased prediction of behaviour disorders. Br J Psychiatry 2009, 195:249-256.

doi:10.1186/1753-2000-8-19

Cite this article as: Möricke et al:: Different stability of social-communication problems and negative demanding behaviour from infancy to toddlerhood in a large Dutch population sample. Child and Adolescent Psychiatry and Mental Health 2014 8:19.

\section{Submit your next manuscript to BioMed Central and take full advantage of:}

- Convenient online submission

- Thorough peer review

- No space constraints or color figure charges

- Immediate publication on acceptance

- Inclusion in PubMed, CAS, Scopus and Google Scholar

- Research which is freely available for redistribution 